\title{
Pressure simulation of an electro-hydraulic proportional piston pump
}

\author{
Shi Jinyan \\ (Hunan Railway Professional Technology College, ZhuZhou HN412001, P. R. China) \\ shijinyan2008@126.com
}

Key words:Electro-hydraulic proportional technology; plunger pump; pressure; simulation

Abstract: In this paper, the pressure model of an electro-hydraulic proportional variable plunger pump is set up through mathematical modeling, and the simulation analysis is carried out with the MATLAB tool. The dynamic response characteristics are obtained, which provides some reference for the research of the electro-hydraulic proportional variable plunger pump.

\section{Composition of an electro-hydraulic proportional piston pump}

Electro-hydraulic proportional control technology is a control technology that converts analog or digital signals into continuous flow or pressure in the hydraulic system. It is an electro-hydraulic control system which has a certain control precision developed to meet the requirements of modern industry.

Applying the electro-hydraulic proportional control technology to the control of the variable pump is to change the pressure difference between the two ends of the pressure difference control valve through the change of the system load, so as to change the flow of the oil in the control plunger cavity, change the stroke of the control plunger, change the inclined angle of the plunger pump, change the output flow of the plunger pump, and change the proportion of the electric and liquid. The composition of the plunger pump is shown in Fig. 1.

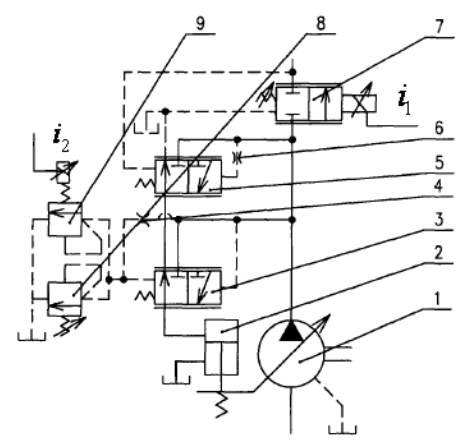

Fig. 1 The composition of the electro-hydraulic proportional piston pump

1- variable piston pump; 2- control plunger; 3- differential pressure control valve; 4- throttle orifice;

5- flow control valve; 6- throttle orifice; 7- electro hydraulic proportional flow valve;

8- safety valve; 9- electro-hydraulic proportional relief valve

\section{The establishment of pressure model}

According to the continuity equation of flow, the output flow of the pump is composed of the following parts:

$$
Q_{P}=\frac{V}{E} \frac{d P}{d t}+\xi_{P} P+Q_{3}+A_{3} \frac{d x_{3}}{d t}+Q_{L}+Q_{4}
$$


$Q_{p}$ is the output flow of the pump, $\mathrm{m}^{3} / \mathrm{s} ; \mathrm{V}$ is the volume of the high pressure cavity of the pump, $\mathrm{m}^{3}$;

$\mathrm{E}$ is the modulus of elasticity of hydraulic oil, $\mathrm{Pa} ; \mathrm{P}$ is the output pressure of the pump,Pa; $\xi_{p}$ is the leakage coefficient in the pump; $Q_{3}$ is the through the pressure difference control valve $3, \mathrm{~m}^{3} / \mathrm{s} ; \mathrm{A}_{3}$ is pressure difference control valve 3 valve core end area, $\mathrm{m}^{2}$;

$\mathrm{x}_{3}$ is the displacement of the 3 valve core moving by the pressure difference control valve, $\mathrm{m}$;

$Q_{L}$ is the flow of flow to the load, $\mathrm{m}^{3} / \mathrm{s}$;

$\mathrm{Q}_{4}$ is the flow through the throttle valve $4, \mathrm{~m}^{3} / \mathrm{s}$;

Linearization of the formula (1) and then Laplace transform, we can obtain as follows:

$$
Q_{P}(s)-Q_{3}-Q_{4}-Q_{L}-A_{3} s X_{3}(s)=\left(\frac{V}{E} s+\xi_{p}\right) P(s)
$$

We can get the relationship between pump output pressure $\mathrm{P}(\mathrm{s})$ and flow rate $Q_{\mathrm{p}}$ from formula (2).

We can get the relationship between piston displacement $\mathrm{x}_{\mathrm{c}}(\mathrm{s})$ and pump output flow $Q_{\mathrm{p}}$ is as follows:

$$
x_{c}(s)=\frac{A_{c}}{M_{c} s^{2}+\left(f_{c}+g_{2}\right) s+\left(g_{1}+k_{e}\right)} P_{3}(s)
$$

$\mathrm{Mc}$ is the mass of the plunger, $\mathrm{kg}$;

$\mathrm{Fc}$ is the viscosity coefficient between the plunger and the sleeve;

Ac is the end area of plunger, $\mathrm{m}^{2}$;

$\mathrm{x}_{\mathrm{c}}$ is displacement of plunger, $\mathrm{m}$;

$K_{x}$ is elastic stiffness of a skew plate, $N / m$;

$\mathrm{L}_{1}$ is the distance between the plunger and the center of the cylinder block, $\mathrm{m}$;

$\mathrm{L}_{2}$ is the distance between the slanted disc spring and the center of the cylinder body, $\mathrm{m}$;

$\mathrm{E}$ is the center distance of inclined disk center and cylinder block, $\mathrm{m}$;

$$
\mathrm{k}_{e}=\mathrm{k}_{\mathrm{x}}\left(\frac{\mathrm{L}_{2}+e}{\mathrm{~L}_{1}-\mathrm{e}}\right)^{2}
$$

According to the continuity equation of flow, the flow rate into the plunger chamber is:

$$
Q_{3}(s)=A_{c} s X_{c}(s)+\frac{V_{c}}{E} S P_{3}(s)+\xi_{c} P_{3}(s)
$$

$\mathrm{Vc}$ is the volume of the high pressure cavity of the plunger, $\mathrm{m}^{3}$;

$\xi_{c}$ is the leakage coefficient of plunger pair;

The relationship between P3 (s) and $\mathrm{x}_{3}(\mathrm{~s})$ is as follows,

$$
\mathrm{K}_{03} \mathrm{X}_{3}(\mathrm{~s})+\mathrm{K}_{\mathrm{P} 3} \mathrm{P}(\mathrm{s})-\mathrm{A}_{\mathrm{c}} \mathrm{s} \mathrm{X}_{\mathrm{c}}(\mathrm{s})=\left(\frac{\mathrm{V}_{\mathrm{c}}}{\mathrm{E}} \mathrm{s}+\left(\xi_{\mathrm{c}}+\mathrm{K}_{\mathrm{P} 3}\right)\right) \mathrm{P}_{3}(\mathrm{~s})
$$

From the electro-hydraulic proportional overflow valve 9, we can obtain that:

$$
x_{9}(s)=\frac{\left(A_{9}-0.57 W_{9} X_{90}-C_{3}\right) P_{9}(s)-K_{2}(s)}{M_{9} s^{2}+L C_{d} W_{9} C_{2} s+0.57 W_{9} P_{90}}
$$


$\mathrm{K}$ is the electromagnetic force coefficient of the valve 9 electromagnet, N/A;

$\mathrm{i}_{2}$ is valve 9 current in electromagnetic iron, $\mathrm{A}$;

$\mathrm{W}_{9}$ is the area gradient of valve 9 valve core, $\mathrm{m}$;

$\mathrm{M}_{9}$ is the quality of valve 9 valve core, $\mathrm{kg}$;

The flow equation of the throttle valve 4 is

$Q_{4}=C_{d} a_{0} \sqrt{\frac{2}{\rho}\left(P-P_{9}\right)}$

$C_{d}$ is the discharge coefficient;

$\mathrm{a}_{0}$ is the flow area of the throttle valve, $\mathrm{m}^{2}$;

Linearization of the formula (7) and then Laplace transform, we can obtain as follows:

$Q_{4}(s)=C_{d} a_{0} \frac{1}{\sqrt{2 \rho\left(P_{0}-P_{90}\right)}}\left(P(s)-P_{g}(s)\right)$

According to the flow continuity equation, it can be obtained

$$
Q_{4}(s)=Q_{9}(s)
$$

From the formula (8) and (9), it can be obtained

$\left(\frac{V_{9}}{B} s+C_{31}+C_{4}\right) P_{9}(s)=C_{4} P(s)-\left(A_{9} s+C_{1} \sqrt{P_{90}}\right) x_{9}(s)$

In the formula, $C_{31}=\frac{C_{d} W_{9} x_{90} \text { sin } a}{C_{2}}, C_{4}=C_{d} a_{0} \frac{1}{\sqrt{2 \rho\left(P_{0}-P_{90}\right)}}$

$\rho$ is oil density, $\mathrm{kg} / \mathrm{m}^{3}$.

According to the formula (1) (10), we can get the relationship between the current $\mathrm{i}_{2}$ (s) of the electromagnet and the output pressure of the electro-hydraulic proportional pump P (s).

\section{Pressure simulation}

The initial parameters of the system are as follows: $\mathrm{E}=2.01 \times 10^{9} \mathrm{~Pa} ; \rho=880 \mathrm{~kg} / \mathrm{m}^{3} ; \mathrm{K}=64.4$; $\mathrm{i}=500 \mathrm{~mA} ; \mathrm{Cd}=0.63 ; \mathrm{L} 1=80 \mathrm{~mm}, \mathrm{~L} 2=70 \mathrm{~mm} ; \mathrm{e}=7 \mathrm{~mm} ; \mathrm{M}_{9}=0.005 \mathrm{~kg} ; \mathrm{d}_{4}=1.2 \mathrm{~mm}$ 。 The simulation analysis of the model is carried out. Simulation analysis shows that the dynamic response curve of the outlet pressure of the electro-hydraulic proportional variable piston pump is shown in Fig. 2. As shown in Fig. 2, the steady state value of the dynamic response of the plunger pump is $13.2 \mathrm{Mpa}$, the rise time is $6.5 \mathrm{~ms}$, the adjustment time is $23 \mathrm{~ms}$, and the overshoot is $8.2 \%$.

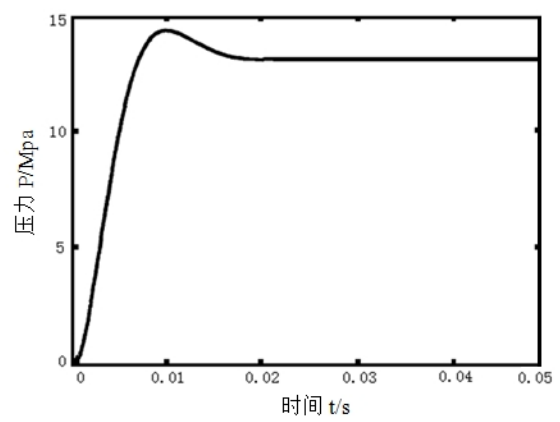

Fig. 2 Dynamic response curve of outlet pressure of electro-hydraulic proportional variable displacement piston pump 


\section{Conclusion}

In this paper, a pressure model of an electro-hydraulic proportional piston pump is established and simulated. The dynamic response characteristic curve is obtained. The steady state value is $13.2 \mathrm{Mpa}$, the rising time is $6.5 \mathrm{~ms}$, the adjustment time is $23 \mathrm{~ms}$, and the overshoot is $8.2 \%$. It provides a reference for the research of electro-hydraulic proportional variable piston pump.

\section{Acknowledgment}

This work was supported by A Project Supported by Scientific Research Fund of Hunan Provincial Education Department (No. 17B179)

\section{Reference}

[1]Xie Jian, Li Taisong. Study on the influence factors and compensation methods of electro-hydraulic proportional valve [J]. Hydraulic pneumatic and seal, 2016 (9)

[2]Liu Xin, Deng Sanpeng. Application of electro-hydraulic proportional technology in large hydraulic jack up system [J]. Science and technology economic guide, 2016 (16)

[3]P.Kaliafetis, Th.Costopoulos. Modeling and Simulation of an Axial Control Piston Variable Displacement Pump with Pressure control.Mech-MachTheory,vol.30,No4,2005

[4]Huang Minghui, Wang Guo Zhi, Wu Wenhai, Deng Bin. Simulation of the pressure characteristic of the electro-hydraulic proportional variable piston pump closed loop system [J]. Hydraulic pneumatic and seal, 2007 (3) 